\title{
Evaluation of Demographic, Clinical, and Etiological Data of Patients Admitted to Cardiology Clinics And Diagnosed with Left Ventricular Hypertrophy (LVH) on Electrocardiography And/Or Echocardiography: LVH-TR
}

Mehmet Kis ( $\nabla$ drmehmet.kis@hotmail.com )

Silopi State Hospital https://orcid.org/0000-0003-0775-8992

\section{Yasemin Dogan}

Kayseri City Education and Research Hospital: Kayseri Sehir Egitim ve Arastirma Hastanesi

Abdullah Yildirim

SBU Adana City Training and Research Hospital: SBU Adana Sehir Egitim ve Arastirma Hastanesi

Tuncay Guzel

Akhisar State Hospital

Lutfu Bekar

Hitit University Faculty of Medicine: T C Hitit Universitesi Tip Fakultesi

Onur Akhan

Bilecik State Hospital

Mustafa Dogdus

Usak University: Usak Universitesi

Hazar Harbalıoglu

Duzce Ataturk State Hospital

Dilay Karabulut

Istanbul Bakirkoy Dr Sadi Konuk Training and Research Hospital: Istanbul Bakirkoy Dr Sadi Konuk

Egitim ve Arastirma Hastanesi

Elton Soydan

Ege University Faculty of Medicine: Ege Universitesi Tip Fakultesi

Selvi Oztas

Bursa City Hospital

Ahmet $\mathrm{Oz}$

Istanbul Training and Research Hospital

Gulay Gok

Istanbul Medipol University: Istanbul Medipol Universitesi

Zeynep Kolak 
Istanbul Dr Siyami Ersek Thoracic and Cardiovascular Surgery Training and Research Hospital: Istanbul Dr Siyami Ersek Gogus Kalp ve Damar Cerrahisi Egitim ve Arastirma Hastanesi

\section{Ercan Aksit}

Çanakkale Onsekiz Mart University Faculty of Medicine: Canakkale Onsekiz Mart Universitesi Tip Fakultesi

\section{Suleyman Anil Sarica}

Bayburt State Hospital: Bayburt Devlet Hastanesi

\section{Murat Bayrak}

Antalya Kepez State Hospital

\section{Berkay Ekici}

Lokman Hekim University: Lokman Hekim Universitesi

\section{Oguzhan Birdal}

Ataturk University Faculty of Medicine: Ataturk Universitesi Tip Fakultesi

\section{Berat Uguz}

Bursa City Hospital

\section{Mesut Gitmez}

Batman Training and Research Hospital

\section{Nihan Caglar}

Bakirkoy Dr Sadi Konuk Training and Research Hospital: Istanbul Bakirkoy Dr Sadi Konuk Egitim ve Arastirma Hastanesi

\section{Gul llayda Berk}

Antalya Atatürk State Hospital: Antalya Ataturk Devlet Hastanesi

\section{Mustafa Oguz}

Van Training and Research Hospital: Van Egitim ve Arastirma Hastanesi

\section{Ali Nazmi Calik}

Istanbul Dr Siyami Ersek Thoracic and Cardiovascular Surgery Training and Research Hospital: Istanbul Dr Siyami Ersek Gogus Kalp ve Damar Cerrahisi Egitim ve Arastirma Hastanesi

\section{Salih Kilic}

SBU Adana City Training and Research Hospital: SBU Adana Sehir Egitim ve Arastirma Hastanesi

\section{Mehdi Zoghi}

Ege University Faculty of Medicine: Ege Universitesi Tip Fakultesi

\section{Asim Oktay Ergene}

Dokuz Eylul University Faculty of Medicine: Dokuz Eylul Universitesi Tip Fakultesi

\section{Research Article}

Keywords: left ventricular hypertrophy, electrocardiography, transthoracic echocardiography, Fabry, amyloidosis 
Posted Date: February 9th, 2022

DOI: https://doi.org/10.21203/rs.3.rs-1331912/v1

License: (c) (i) This work is licensed under a Creative Commons Attribution 4.0 International License. Read Full License 


\section{Abstract}

Purpose: Left ventricular hypertrophy $(\mathrm{LVH})$ is a common condition in the population and potentially modifiable cardiovascular (CV) risk factor often overlooked in clinical practice. Early diagnosis and treatment-related regression of $\mathrm{LVH}$ reduces adverse $\mathrm{CV}$ events and improves survival. For this reason, we planned to LVH-TR trial to determine the etiological causes of LVH, the symptoms that patients present with, and the effects of demographic characteristics of patients on LVH.

Methods: Our study is a multicenter, national, observational study and included 886 patients who applied to the cardiology clinics in 23 centers between February 2020 and August 2021. In the initial evaluation, the Fabry and amyloidosis algorithm was followed in patients whose traditional etiologic cause(s) could not be identified (LVH of unknown origin).

Results: The mean age of the patients was 58.92 years, and $60.3 \%$ of them were male. More than $90 \%$ of the patients were NYHA class I \& II patients. The most common etiological causes of LVH in our study were hypertension with a rate of $69.7 \%$, heart valve disease with $10.2 \%$, and hypertrophic cardiomyopathy with $9.2 \%$. Athlete's heart was detected in 8 patients, LV non-compaction was detected in 4 patients.

The rate of LVH of unknown cause was $18.8 \%$. Fabry disease was suspected in 143 patients, and Amilodose disease was suspected in 16 patients. There were 43 (4.85\%) patients with low aGalactosidase A enzyme levels in patients who requested enzyme testing. GLA gene mutation analysis was positive in $1.58 \%$ of all patients, and these patients were diagnosed with Fabry, and $15(1.69 \%)$ patients were diagnosed with amyloidosis by endomyocardial biopsy method.

Conclusion: In the etiology of left ventricular hypertrophy, the rate of LVH of unknown cause was high. Fabry Disease and Amyloidosis should be considered primarily in this patient group. Early diagnosis of the disease by following the schemes leading to Fabry and Amyloidosis was essential in starting treatment before the progression of the disease.

\section{Introduction}

Left ventricular hypertrophy (LVH) is an abnormal increase in the mass of the left ventricular (LV) myocardium caused by the chronically increased workload on the heart (1).LVH is the most common result of the heart trying to pump blood against the high afterload, as in hypertension (HT) and aortic stenosis (AS) (2). Although HT is the most common cause of LVH, LVH can also be found in athletes and cardiomyopathies or storage disorders such as amyloidosis. In addition, genetic diseases also play an essential role in the pathogenesis of $\operatorname{LVH}(3,4)$. Fabry disease (FD) is another disease that should be considered in patients with LVH (5).

FD is an X-linked lysosomal storage disorder due to a-galactosidase A ( $a-G a l$ A) enzyme deficiency resulting in progressive accumulation of globotriaosylceramide (Gb3) in various organ tissues (6). Most prevalence data for FD are based on systematic screening of high-risk populations such as hypertrophic 
cardiomyopathy $(\mathrm{HCM})$, cryptogenic stroke, or end-stage renal disease $(7,8)$. In patients with unexplained $\mathrm{LVH}$, the prevalence of FD ranges from $0-12 \%$ in highly selected cohorts $(6,9,10)$. Data on FD's frequency and clinical features in the LVH population are scarce. Affected individuals have a variety of clinical manifestations, including neurological, gastrointestinal, renal, and cardiac (11). In Fabry patients with cardiac involvement, echocardiography $(\mathrm{ECHO})$ typically shows progressive increased LV wall thickness, especially concentric hypertrophy, AV valve thickness, papillary muscle thickness, and right ventricular free wall thickness (12-14). It has been reported that electrocardiographic (ECG) changes may be different from prolonged QRS duration to the increase in the Sokolow-Lyon index in $\operatorname{FD}(15,16)$. Early diagnosis of FD is imperative, as evidence suggests that LVH can be prevented or regressed with early treatment with enzyme replacement therapy (ERT); moreover, the response to ERT is poor in advanced FD (17).

Cardiac amyloidosis (CA) is an infiltrative disease caused by the extracellular accumulation of insoluble amyloid proteins in the myocardium (18). Due to these infiltrations, progressive increase ventricular wall thickness and stiffness, and thus CA mimics LVH. Among all the characteristic $\mathrm{ECHO}$ findings of $\mathrm{CA}$, the most common one is LVH (19). Therefore, ECHO is usually the first test to cast doubt on the diagnosis of $\mathrm{CA}(18,19)$. A definitive diagnosis of CA requires confirmation of amyloid deposits in cardiomyocytes by endomyocardial biopsy, which can cause fatal complications (20). Bone scintigraphy, including technetium pyrophosphate (99mTc-PYP) scintigraphy and cardiac magnetic resonance imaging (CMRI), are helpful for noninvasive diagnosis of CA; however, they are costly and not available in all facilities (21). Therefore, CA should be screened appropriately in patients with LVH to identify those requiring further investigation (22). Of the etiologies leading to LVH and worse cardiac outcomes, cardiac amyloidosis is one of the most common factors (23). Amyloid infiltration of the heart typically leads to restrictive cardiomyopathy and progressive congestive heart failure (HF), and sudden death. In conclusion, early diagnosis and specific management are critical determinants in the prognosis of these patients (24).

LVH is a vital independent risk factor for cardiovascular morbidity and mortality (25). Early diagnosis and treatment-related regression of LVH reduces adverse cardiovascular events and improves survival $(1,2$, 26). Therefore, we planned to perform an LVH-TR study to determine the etiologic causes of LVH, the symptoms presented by the patients, and the effects of patients' demographic characteristics on LVH.

\section{Materials And Methods}

Our study was a multicenter, national, and observational study. The number of centers participating in our study was 23 . The study included 886 patients who applied to cardiology clinics between February 2020 and August 2021 and were diagnosed with LVH by ECG/ECHO. Signed voluntary consent forms were obtained from all patients. Our exclusion criteria can be listed as younger than 18 years, ECG and ECHO recordings not optimal for analysis. Demographic data, biochemical parameters, and imaging findings of the patients were recorded. 
$\mathrm{ECHO}$ images were obtained in 4 standard views (parasternal long axis, parasternal short axis, apical twochamber, and apical four-chamber) using the methods recommended by the American Society of Echocardiography guidelines (27).

Sokolov-Lyon criteria ( $\mathrm{S}$ wave depth in $\mathrm{V} 1+$ longest $\mathrm{R}$ wave height in $\mathrm{V} 5$ - V6 $>35 \mathrm{~mm}$ ) were used to diagnose LVH in ECG. Left ventricular mass index (LVMI) $(0.8 \times(1.04 \times[(I V S d+$ LVIDd + PWTd $) 3-$ LVIDd3]) +0.6 and normalized to body surface area) was used to diagnose LVH by ECHO. RWT (regional wall thickness) was calculated with the equation $2 \times$ LVPWd/LVDd.

Concentric LVH was defined as an RWT greater than 0.42, LVMI greater than $115 \mathrm{~g} / \mathrm{m}^{2}$ in men and 95 $\mathrm{g} / \mathrm{m}^{2}$ in women; eccentric LVH was defined as an RWT less than 0.42 , LVMI greater than $115 \mathrm{~g} / \mathrm{m}^{2}$ in men, and greater than $95 \mathrm{~g} / \mathrm{m}^{2}$ in women; remodeling LVH was defined as an RWT greater than 0.42 , LVMI less than $115 \mathrm{~g} / \mathrm{m}^{2}$ in men and less than $95 \mathrm{~g} / \mathrm{m}^{2}$ in women. LVH is defined as recommended in the $2018 \mathrm{ESH} / \mathrm{ESC}$ guidelines (28).

The Fabry and amyloidosis algorithm was followed in patients whose definitive etiologic cause(s) could not be identified (LVH of unknown cause) in the initial evaluation (figure 1 and 2) (29-34).

A dry blood sample was sent from male patients who suspected FD. a-Gal An enzyme level was checked, and genetic testing was performed on patients with low enzyme levels. Female patients with suspected FD were genetically tested with GLA Gene Mutation Analysis. Peripheral venous blood samples were taken from each patient. The blood was aspirated on dry blood sample paper and sent to an external laboratory to diagnose genetic diseases.

In patients suspected of CA, evaluation with MRI, tissue biopsy, bone scintigraphy with Tc-PYP, Tc-DPD, or Tc-MDP were performed within the possibilities of the centers participating in the study.

\section{a-Gal A enzyme activity test}

a-Gal An enzyme activity was based on a fluorimetric method's dry blood test. Substrate: 4Methylumbelliferyl-a-D-galactopyranoside (TRC, M334475). Inhibitor: N-Acetyl-D-galactosamine (Sigma, A2795). Samples (3 mm DBS punch+inhibitor+substrate) were incubated for 17 hours at $37^{\circ} \mathrm{C}$, and the reaction was stopped. Fluorescence was recorded at Ex: $366 \mathrm{~nm}$ Em: $442 \mathrm{~nm}$ in the fluorimeter. The calibration curve was created with 4-Methylumbelliferone (Sigma M1381), and the results were evaluated. The usual range of a-Gal A activity was defined as $>2.50 \mathrm{nmol} / \mathrm{mL} / \mathrm{hr}$. This cut-off value was determined by the receiver operating characteristic test by the Duzen Laboratory group.

\section{Mutation analysis}

GLA gene sequence analysis was performed in terms of genotype analysis. The process performed in the Fabry genetic study is the sequencing process performed with the next generation sequencing (NGS) method. PCR products amplified by PCR from the DNA isolated in this procedure were sequenced and compared with the reference sequence (NCBI Genomic Reference Sequence: NG_007119.1, 
NM_000169.2). Among the mutations detected here, those in the coding sequence were reported. In addition, the association of reported mutations with Fabry Disease was added from the "HGMD" database. For mutations not in the database, predictions of model analysis programs such as SIFT, Mutation t@ster, PolyPhen-2 have been added.

Ethics committee approval of our study was obtained from the Bakırköy Dr.Sadi Konuk Training and Research Hospital Clinical Research Ethics Committee on 20.01.2020 with the decision number 2020-0221.

ClinicalTrials.gov application has been made for our study, and its identifier number was NCT04275882.

\section{Statistical analysis}

IBM SPSS Statistics 25.0 Program was used. "Kolmogorov-Smirnov" and "Shapiro-Wilk" tests were applied to determine whether the study data showed normal distribution. Descriptive statistics were prepared to include frequency (n), mean and standard deviation values. In addition, frequencies and percentages are given for categorical variables.

\section{Results}

The mean age of 886 patients included in the study was $58.92( \pm 14.05)$ years, and the male sex ratio was $60.3 \%$. The mean body mass index (BMI) was $28.25( \pm 4.65) \mathrm{kg} / \mathrm{m}^{2}$. The patients' mean systolic and diastolic blood pressures were $138.56( \pm 21.85) \mathrm{mmHg}$ and $82.45( \pm 12.84) \mathrm{mmHg}$, respectively. The patients' demographic data included in the study are summarized in Table 1. 
Table 1

Demographic and clinical characteristics of the study population

\begin{tabular}{|c|c|}
\hline Demographic feature & $n=886$ \\
\hline Age, years, mean \pm std & $58.92 \pm 14.05$ \\
\hline Male sex, n (\%) & $534(60.3)$ \\
\hline Body Mass Index, $\mathrm{kg} / \mathrm{m}^{2}$, mean \pm std & $28.25 \pm 4.65$ \\
\hline Systolic Blood Pressure, mean \pm std & $138.56 \pm 21.85$ \\
\hline Diastolic Blood Pressure, mean \pm std & $82.45 \pm 12.84$ \\
\hline Chest pain, $\mathrm{n}(\%)$ & $270(30.5)$ \\
\hline Palpitation, n (\%) & $249(28.1)$ \\
\hline Shortness of breath, n (\%) & $427(48.2)$ \\
\hline Syncope, n (\%) & $34(3.8)$ \\
\hline Smoking, n (\%) & $198(22.3)$ \\
\hline Anemia, n (\%) & $173(19.5)$ \\
\hline Atrial fibrilation, $\mathrm{n}(\%)$ & $97(10.9)$ \\
\hline CAD, CABG or PCI history, n (\%) & $299(33.7)$ \\
\hline Hipertansiyon, n (\%) & $642(72.5)$ \\
\hline Stroke/ TIA, n (\%) & $72(8.1)$ \\
\hline Hiperlipidemi, n (\%) & $225(25,4)$ \\
\hline Diyabetes mellitus, n (\%) & $240(27.1)$ \\
\hline
\end{tabular}

The most common cause of etiology was HT, with a rate of $69.7 \%$. Heart valve disease was the other most common cause with a rate of $10.2 \%$ and $\mathrm{HCM}$ with $9.2 \%$. Athlete's heart was detected in 8 patients, LV non-compaction was detected in 4 patients. The rate of obesity alone in the etiology of LVH was $1.5 \%$, chronic renal failure was $1.4 \%$, and diabetes mellitus was $2.9 \%$. Information on the etiological factors of $\mathrm{LVH}$ is summarized in figure 3.

Patients whose etiology could not be determined at the first stage were defined as LVH of unknown cause. Patients of unknown cause constituted $18.8 \%$ of the patients. Fabry disease was suspected in 143 patients, and Amilodose disease was suspected in 16 patients. There were 43 (4.85\%) patients with low alpha-galactosidase A enzyme levels in patients who requested enzyme testing. GLA Gene Mutation Analysis was positive in $1.58 \%$ of the patients, and these patients were diagnosed with Fabry. 
Stroke/transient ischemic attack was detected in $12.5 \%$ and chronic renal failure in $18.8 \%$ of Fabry patients. In ECG findings, 1 degree AV block was detected in $14.6 \%$, S wave depth in V1 + the most extended R wave height in V5-V6 was over $35 \mathrm{~mm}$ in $60.4 \%$. Among the $\mathrm{ECHO}$ findings, a binary sign was $8.3 \%$, AV valve thickness increase was $22.9 \%$, papillary muscle hypertrophy was $25 \%$. In Fabry patients with LVH, mean interventricular septal thickness was $16.59 \mathrm{~mm}$, mean LVMI was $167.12 \mathrm{~g} / \mathrm{m}^{2}$, mean left atrial volume index was $34.09 \mathrm{ml} / \mathrm{m}^{2}$, and mean RWT was 0.60 .

In patients with amyloidosis, low QRS voltage was observed in $6(40 \%)$ patients, and a pseudo-infarct pattern was observed in 4 (26.7\%) patients. In ECHO, pericardial effusion was observed in $4(26.7 \%)$ patients, and myocardial ground-glass opacity was observed in $5(33.4 \%)$ patients. Bone scintigraphy in $10(66.7 \%)$ patients and cardiac MRI in $5(33.4 \%)$ patients were considered to have suspected amyloidosis, and cardiac biopsy was performed. Amyloidosis was diagnosed by the endomyocardial biopsy method in $15(1.69 \%)$ patients. Parasternal long axis echocardiographic images of different LVH etiologies are given in figure 4 .

\section{Discussion}

This study demonstrates that the rate of LVH etiology unknown cause was high (18.8\%), apart from traditional etiological factors. Identifying the underlying etiology of LVH remains a challenging but crucial clinical problem, with significant therapeutic and prognostic implications. Contrary to popular belief, the frequency of Fabry and Amyloidosis was high in this patient group. By following the steps in the diagnostic scheme, the probability of making the diagnosis of Fabry and amyloidosis was increased. In this way, early diagnosis will increase the likelihood of patients benefiting more from treatment. Furthermore, our study showed that even patients with low a-Gal A enzyme levels may not have mutations in the GLA gene.

In our study, the most common etiological factors are compatible with the literature (31). In the study of Shu-Xia et al. conducted with 4270 hypertensive patients, LVH was detected in $42.7 \%$ of them by ECHO (30). The other most common causes of LVH in the general population are; valve diseases and HCM (25, 33-37). It is still controversial whether type 2 diabetes mellitus (T2DM) is associated with increased left ventricular (LV) mass regardless of body size. In a study that included 1932 patients $(67.9 \pm 9.6$ years; 769 males and 1163 females; 443 DM and 1489 non-DM) patients, LV mass ( $189 \pm 60$ vs. $174 \pm 59 \mathrm{~g} ; \mathrm{p}<0.0001)$ was found higher in the DM group than in the non-DM group. In addition, in multivariate analysis, Type 2 DM was independently associated with increased LV mass $(P=0.03)$. The presence of type $2 \mathrm{DM}$ was found to be associated with an increased risk of LV hypertrophy (adjusted odds ratio $1.46 ; 95 \% \mathrm{Cl}, 1.13-$ $1.88, \mathrm{P}=0.004)$ (38). DM was detected as an isolated etiological factor in $2.9 \%$ of $\mathrm{LVH}$ patients in our study.

HCM characterized by increased LV wall thickness is the most common non-ischemic cardiomyopathy with an estimated prevalence of 1 in 500 people (39). Over the past 10 to 20 years, investigators have been able to rapidly assemble large patient cohorts with ease, exceeding expectations based on earlier 
perceptions of disease frequency. However, sometimes there may be difficulties distinguishing HCM from other conditions, such as athlete's heart and hypertensive heart disease. Especially a proportion of hypertensive patients may have more substantial hypertrophy (up to $16 \mathrm{~mm}$ ) and fall into a "gray zone" in which ECG and ECHO features are indistinguishable from HCM.

Fabry disease should be considered in the differential diagnosis in patients with LVH. The FACSS study assessed the prevalence of Fabry disease in 100 male patients over 30 years of age with unexplained LVH. The prevalence of Fabry diagnosed with a-galactosidase A activity was 4\% (9). In another study, 362 men and 178 women with LVH, who constitute the majority of hypertensive patients, mutations in the GLA gene were found in six patients (0.9\%) (40). In a study examining plasma a-galactosidase A activity in 177 men with $\mathrm{HCM}$, very low a-galactosidase A activity was found in two (1.1\%) patients (41).In another study involving 34 consecutive female patients diagnosed with HCM, it was reported that Fabry disease might be responsible for up to $12 \%$ of late-onset HCM (10). Barman et al. reported that $2(1.05 \%)$ patients were diagnosed with Fabry disease out of 190 patients with unexplained LVH (14). Inclusion of the specific patient group and/or only the wall thickness in the definition of LVH is seen as a disadvantage of these studies. However, in our study, not a specific patient group, all consecutively diagnosed patients with LVH were included. LVMI was used as LVH criteria, and Fabry and Amyloidosis algorithms (figure 2 and 3 ) were followed in patients with LVH of unknown cause. So, according to the results of our study, Fabry disease was detected in $1.59 \%$ of LVH patients.

Recent data suggest that may not be a rare condition. In a prospective study, nuclear scintigraphy scans showed that $13.3 \%$ of a patient aged $\geq 60$ years with left ventricular hypertrophy $(\geq 12 \mathrm{~mm})$ and hospitalized for HFpEF had wtTTR amyloidosis (18). In another study, the rate of cardiac amyloidosis was $17 \%$ in 109 patients with HFpEF and $5 \%$ in 131 control patients without HFpEF (42). In our study, cardiac amyloidosis was found at a rate of $1.69 \%$ in the LVH population. However, Beneyto et al. conducted etiological research in 591 patients with left ventricular hypertrophy. They found that CA led LVH etiologies (34.3\%), followed by sarcomeric HCM (S-HCM, 32.1\%), hypertensive cardiomyopathy (21.7\%), unknown etiology (7.6\%), and other (4.2\%), including Anderson Fabry's disease (1.7\%). The study excluded patients presenting with severe aortic valve stenosis, bioprosthetic aortic valve stenotic degeneration, and obstructive subaortic membranes. In the study, HT was present in 372 patients (62.9\%), but HT was accepted as the etiology in $21 \%$ of the patients. Therefore, excluding other causes such as amyloidosis is necessary, especially in hypertensive patients with additional clinical findings (43).

LVH of unknown cause comprised 18.8\% (167) of all LVH patients. Fabry and/or Amyloidosis tests could not be performed in eight of these patients. In patients with LVH of unknown cause, myocardial infiltration diseases such as amyloidosis, metabolic diseases such as Fabry, Pompe, and Danon, and mitochondrial myopathies should be suspected $(29,37-45)$.

\section{Limitations}


The main limitation of our study was that the TTE devices and techniques used in the 23 centers participating in the study were different. Although Fabry enzyme and genetic testing were performed in a single laboratory, each participant performed the analysis of electrocardiographic and echocardiographic findings himself/herself. Another limitation is that we could not investigate very rare storage diseases. We focused on Fabry and amyloidosis.

\section{Conclusion}

Although HT, valvular disease, and cardiomyopathies are responsible for most causes of LVH, it is essential to investigate patients with unexplained LVH as many causes are treatable. In the etiology of $\mathrm{LVH}$, the rate of LVH of unknown cause was high. Therefore, FD and CA should be considered primarily in this patient group. By following the schemes leading to the diagnosis of FD and CA, early diagnosis of the disease was critical in starting treatment before disease progression. Low a-Gal A enzyme levels are not sufficient in diagnosing FD, and GLA gene mutation analysis should be performed for a definitive diagnosis.

\section{Declarations}

\section{Conflict of Interest}

The authors declare that there was no conflict of interest regarding this article.

\section{Financial Resource}

No financial resources have been used for this article.

\section{Ethics committee}

Ethics committee approval of our study was obtained from the Bakırköy Dr.Sadi Konuk Training and Research Hospital Clinical Research Ethics Committee on 20.01.2020 with the decision number 2020-0221.

\section{References}

1-) Lorell BH, Carabello BA (2000). Left ventricular hypertrophy: pathogenesis, detection, and prognosis. Circulation 102:470-479.

2-) Bornstein AB, Rao SS, Marwaha K (2021). Left Ventricular Hypertrophy. In: StatPearls [Internet]. Treasure Island (FL):PMID: 32491466. https://www.ncbi.nlm.nih.gov/books/NBK557534/.

3-) Ana Baptista, Pedro Magalhães, Sílvia Leão, et al (2015). Screening for Fabry Disease in Left Ventricular Hypertrophy: Documentation of a Novel Mutation. Arq Bras Cardiol 105(2): 139-144. doi: $10.5935 / a b c .20150090$ 
4-) Coelho T, Maurer MS, Suhr OB (2013). THAOS - The Transthyretin Amyloidosis Outcomes Survey: initial report on clinical manifestations in patients with hereditary and wild-type transthyretin amyloidosis. Curr Med Res Opin 29:63-76

5-) R Menezes Fernandes, O Azevedo, F Cordeiro, A Lourenco (2021). Left ventricular hypertrophy secondary to Fabry disease: mechanical dispersion and arrhythmic burden. European Heart Journal 42 (Supp 1) ehab724.1791, doi:10.1093/eurheartj/ehab724.1791.

6-) Linhart A, Germain DP, Olivotto I, Akhtar MM, Anastasakis A, Hughes D, et al (2020). An expert consensus document on the management of cardiovascular manifestations of Fabry disease. Eur $\mathrm{J}$ Heart Fail 22(7):1076-1096. doi: 10.1002/ejhf.1960.

7-) Reuser AJ, Verheijen FW, Bali D, van Diggelen OP, Germain DP, Hwu WL, et al (2011). The use of dried blood spot samples in the diagnosis of lysosomal storage disorders - current status and perspectives. Mol Genet Metab 104:144-148.

8-) Linthorst GE, Bouwman MG, Wijburg FA, Aerts JM, Poorthuis BJ, Hollak CE (2010). Screening for Fabry disease in high-risk populations: a systematic review. J Med Genet 47:217-222

9-) Palecek T, Honzikova J, Poupetova H, Vlaskova H, Kuchynka P, Golan L, et al (2014). Prevalence of Fabry disease in male patients with unexplained left ventricular hypertrophy in primary cardiology practice: prospective Fabry cardiomyopathy screening study (FACSS). J Inherit Metab Dis 37(3):455-460. doi: 10.1007/s10545-013-9659-2.

10-) Chimenti C, Pieroni M, Morgante E, Antuzzi D, Russo A, Russo MA, et al (2004). Prevalence of Fabry disease in female patients with late-onset hypertrophic cardiomyopathy. Circulation 110(9):1047-1053. doi: 10.1161/01.CIR.0000139847.74101.03.

11-) Favalli V, Disabella E, Molinaro M (2016). Genetic Screening of Anderson-Fabry Disease in Probands Referred From Multispecialty Clinics. J. Am. Coll Cardiol 68:1037-1050.

12-) Serra W, Marziliano N (2019). Role of cardiac imaging in Anderson-Fabry cardiomyopathy. Cardiovasc Ultrasound 17(1):1. doi: 10.1186/s12947-019-0151-5.

13-) Militaru S, Jurcuț R, Adam R, Roşca M, Ginghina C, Popescu BA (2019). Echocardiographic features of Fabry cardiomyopathy-Comparison with hypertrophy-matched sarcomeric hypertrophic cardiomyopathy. Echocardiography 36(11):2041-2049. doi: 10.1111/echo.14508.

14-) Barman HA, Özcan S, Atıcı A, Özgökçe C, Öztürk A, Kafalı AE, et al (2020). Ratio of Fabry disease in patients with idiopathic left ventricular hypertrophy: A single-center study in Turkey. Anatol J Cardiol 23(2):79-85. doi: 10.14744/AnatolJCardiol.2019.84782.

15-) Zada M, Lo Q, Trivedi SJ, Harapoz M, Boyd AC, Devine K, et al (2022). Electrocardiographic Characteristics and Their Correlation with Echocardiographic Alterations in Fabry Disease. J Cardiovasc 
Dev Dis 9(1):11. doi:10.3390/jcdd9010011

16-) Namdar M (2016). Electrocardiographic Changes and Arrhythmia in Fabry Disease. Front Cardiovasc Med 3:7. doi: 10.3389/fcvm.2016.00007.

17-) Pieroni M, Moon JC, Arbustini E (2021). Cardiac Involvement in Fabry Disease: JACC Review Topic of the Week. J. Am. Coll Cardiol 77:922-936.

18-) González-López E, Gallego-Delgado M, Guzzo-Merello G, de Haro-Del Moral FJ, Cobo-Marcos M, Robles C, et al (2015). Wild-type transthyretin amyloidosis as a cause of heart failure with preserved ejection fraction. Eur Heart J 36(38): 2585-2594, doi: 10.1093/eurheartj/ehv338.

19-) Melero Polo J, Roteta Unceta-Barrenechea A, Revilla Martí P, Pérez-Palacios R, Gracia Gutiérrez A, Bueno Juana $E$, et al (2021). Echocardiographic markers of cardiac amyloidosis in patients with heart failure and left ventricular hypertrophy. Cardiol J. doi: 10.5603/CJ.a2021.0085. Epub ahead of print. PMID: 34355777.

20-) From AM, Maleszewski JJ, Rihal CS (2011). Current status of endomyocardial biopsy. Mayo Clin Proc 86(11):1095-102. https://doi.org/10.4065/mcp.2011.02 96.

21-) Maurer MS, Elliott P, Comenzo R, Semigran M, Rapezzi C (2017). Addressing common questions encountered in the diagnosis and management of cardiac amyloidosis. Circulation 135(14):1357-77. https://doi.org/10.11 61/CIRCULATIONAHA.116.024438

22-) Nakao Y, Saito M, Inoue K, Higaki R, Yokomoto Y, Ogimoto A, et al (2021). Cardiac amyloidosis screening using a relative apical sparing pattern in patients with left ventricular hypertrophy. Cardiovasc Ultrasound 19(1):30. doi: 10.1186/s12947-021-00258-x.

23-) Falk RH (2016). Pondering the prognosis and pathology of Cardiac Amyloidosis: Answers Breed Questions. JACC Cardiovasc Imaging 9:139-141. doi: 10.1016/j.jcmg.2015.07.018.

24-) Cariou E, Bennani Smires Y, Victor G, Robin G, Ribes D, Pascal P, et al (2017). Diagnostic score for the detection of cardiac amyloidosis in patients with left ventricular hypertrophy and impact on prognosis. Amyloid 24(2):101-109. doi: 10.1080/13506129.2017.1333956.

25-) Levy D, Garrison RJ, Savage DD, Kannel WB, Castelli WP, et al (1990). Prognostic implications of echocardiographically determined left ventricular mass in the Framingham Heart Study. N Engl J Med 322:1561-1566.

26-) Giamouzis G, Dimos A, Xanthopoulos A, Skoularigis J, Triposkiadis F (2021). Left ventricular hypertrophy and sudden cardiac death. Heart Fail Rev. doi: 10.1007/s10741-021-10134-5. Epub ahead of print. PMID: 34184173 
27-) Lang RM, Badano LP, Mor-Avi V, Afilalo J, Armstrong A, Ernande L, et al (2015). Recommendations for cardiac chamber quantification by echocardiography in adults: an update from the American Society of Echocardiography and the European Association of Cardiovascular Imaging. J Am Soc Echocardiogr 28: 1-39.e14.

28-) Nardi E, Mulè G, Giammanco A, Mattina A, Geraci G, Nardi C, et al (2021). Left ventricular hypertrophy in chronic kidney disease: A diagnostic criteria comparison. Nutr Metab Cardiovasc Dis. 31(1):137-144. doi: 10.1016/j.numecd.2020.08.028.

29-) Kayıkçıoğlu M, Şimşek E, Kalkan Uçar S, Bayraktaroğlu S, Onay H, Sözmen E, et al (2017). Fabry disease: An overlooked diagnosis in adult cardiac patients. Turk Kardiyol Dern Ars 45(6):549-555. Turkish. doi: 10.5543/tkda.2017.68709.

30-) Losi MA, Nistri S, Galderisi M, Betocchi S, Cecchi F, Olivotto I, et al (2010). Echocardiography in patients with hypertrophic cardiomyopathy: usefulness of old and new techniques in the diagnosis and pathophysiological assessment. Cardiovasc Ultrasound 8:7. doi: 10.1186/1476-7120-8-7.

31-) Yousef Z, Elliott PM, Cecchi F, Escoubet B, Linhart A, Monserrat L, et al (2013). Left ventricular hypertrophy in Fabry disease: a practical approach to diagnosis. Eur Heart J 34(11):802-8. doi: 10.1093/eurheartj/ehs166.

32-) Laney DA, Bennett RL, Clarke V, Fox A, Hopkin RJ, Johnson J, et al (2013). Fabry disease practice guidelines: recommendations of the National Society of Genetic Counselors. J Genet Couns 22:555-64.

33-) Maurer MS, Bokhari S, Damy T, Dorbala S, Drachman BM, Fontana M, et al (2019). Expert Consensus Recommendations for the Suspicion and Diagnosis of Transthyretin Cardiac Amyloidosis. Circ Heart Fail. 12(9):e006075. doi: 10.1161/CIRCHEARTFAILURE.119.006075.

34-) Garcia-Pavia P, Rapezzi C, Adler Y, Arad M, Basso C, Brucato A, et al (2021). Diagnosis and treatment of cardiac amyloidosis: a position statement of the ESC Working Group on Myocardial and Pericardial Diseases. Eur Heart J. 42(16):1554-1568. doi: 10.1093/eurheartj/ehab072.

35-) Kannel WB, Dannenberg AL, Levy D (1987). Population implications of electrocardiographic left ventricular hypertrophy. Am J Cardiol 60:851-931.

36-) Artham SM, Lavie CJ, Milani RV, Patel DA, Verma A, Ventura HO (2009). Clinical impact of left ventricular hypertrophy and implications for regression. Prog Cardiovasc Dis 52:153-67.

37-) Desai CS, Ning H, Lloyd-Jones DM (2012). Competing cardiovascular outcomes associated with electrocardiographic left ventricular hypertrophy: the atherosclerosis risk in communities study. Heart 98:330-4.

38-) Eguchi K, Boden-Albala B, Jin Z, Rundek T, Sacco RL, Homma S, et al (2008). Association between diabetes mellitus and left ventricular hypertrophy in a multiethnic population. Am J Cardiol 101(12):1787- 
91. doi: 10.1016/j.amjcard.2008.02.082.

39-) Maron BJ, Gardin J, Flack JM, Gidding SS, Kurosaki TT, Bild DE (1995). Prevalence of hypertrophic cardiomyopathy in a general population of young adults. Echocardiographic analysis of 4111 subjects in the CARDIA study. Coronary artery risk development in (young) adults. Circulation 92(4):785-789. doi: 10.1161/01.cir.92.4.785.

40-) Terryn W, Deschoenmakere G, De Keyser J, Meersseman W, Van Biesen W, Wuyts B, et al (2013). Prevalence of Fabry disease in a predominantly hypertensive population with left ventricular hypertrophy. Int J Cardiol 167(6):2555-60. doi: 10.1016/j.ijcard.2012.06.069.

41-) Kubo T, Ochi Y, Baba Y, Hirota T, Tanioka K, Yamasaki N, et al (2017). Prevalence and clinical features of Fabry disease in Japanese male patients with diagnosis of hypertrophic cardiomyopathy. $\mathrm{J}$ Cardiol 69(1):302-307. doi: 10.1016/j.jjcc.2016.05.014.

42-) Mohammed SF, Mirzoyev SA, Edwards WD, Dogan A, Grogan DR, Dunlay SM, et al (2014). Left ventricular amyloid deposition in patients with heart failure and preserved ejection fraction. JACC Heart Fail 2:113-22.

43-) Beneyto M, Cariou E, Brunel J, Scripcariu A, Delasnerie H, Brun S, et al (2021). Tip of the iceberg: a tertiary care centre retrospective study of left ventricular hypertrophy aetiologies. Open Heart 8:e001462. doi:10.1136/ openhrt-2020-001462.

44-) Lee DH, Qiu WJ, Lee J, Chien YH, Hwu WL (2014). Hypertrophic cardiomyopathy in pompe disease is not limited to the classic infantile-onset phenotype. JIMD Rep 17:71-75. doi:10.1007/8904_2014_339.

45-) Cheng Z, Cui Q, Tian Z, Xie H, Chen L, Fang L, et al (2012). Danon disease as a cause of concentric left ventricular hypertrophy in patients who underwent endomyocardial biopsy. Eur Heart J 33(5):649-56. doi: 10.1093/eurheartj/ehr420

\section{Figures}




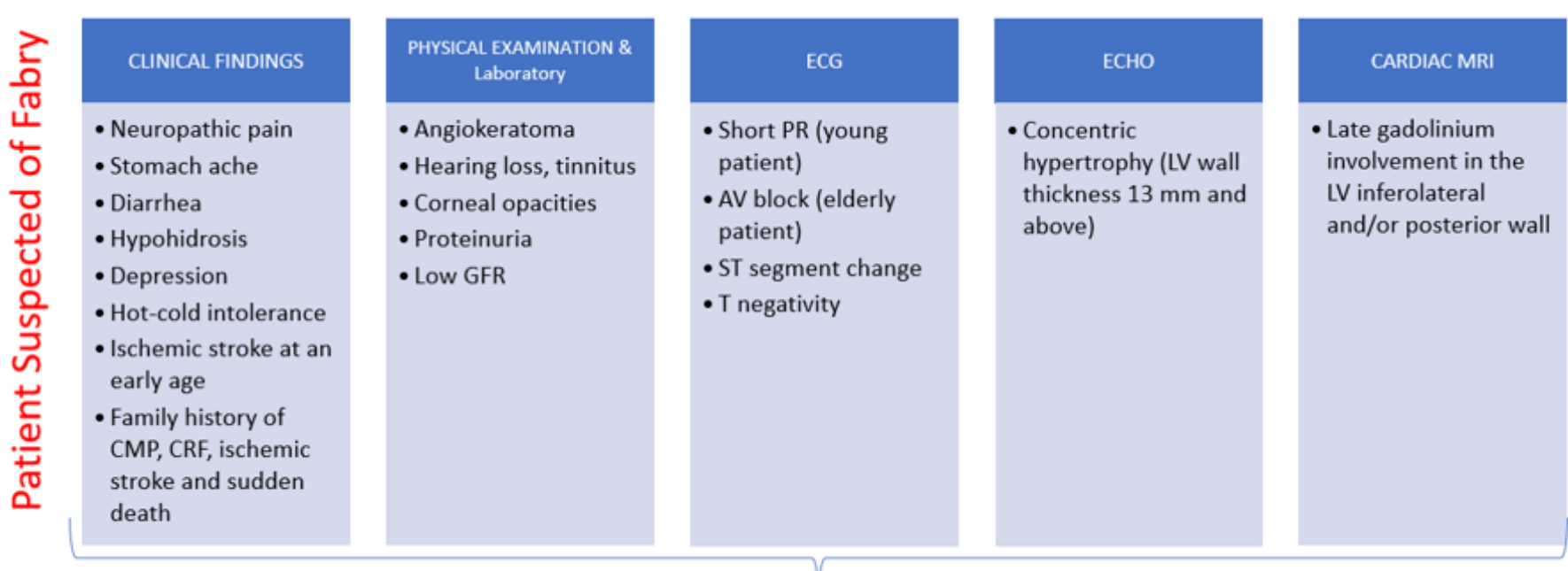

If there are findings mentioned above; FABRY disease was considered!

Complete blood count/dry blood

(Leukocyte $\alpha$-Gal A enzyme activity)

$\alpha$-galactosidase A deficiency

GLA Gene Mutation Analysis

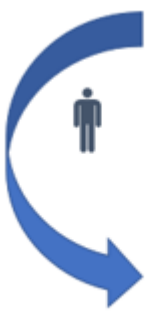

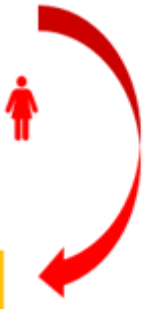

FABRY's DISEASE

\section{Figure 1}

\section{Fabry algorithm}




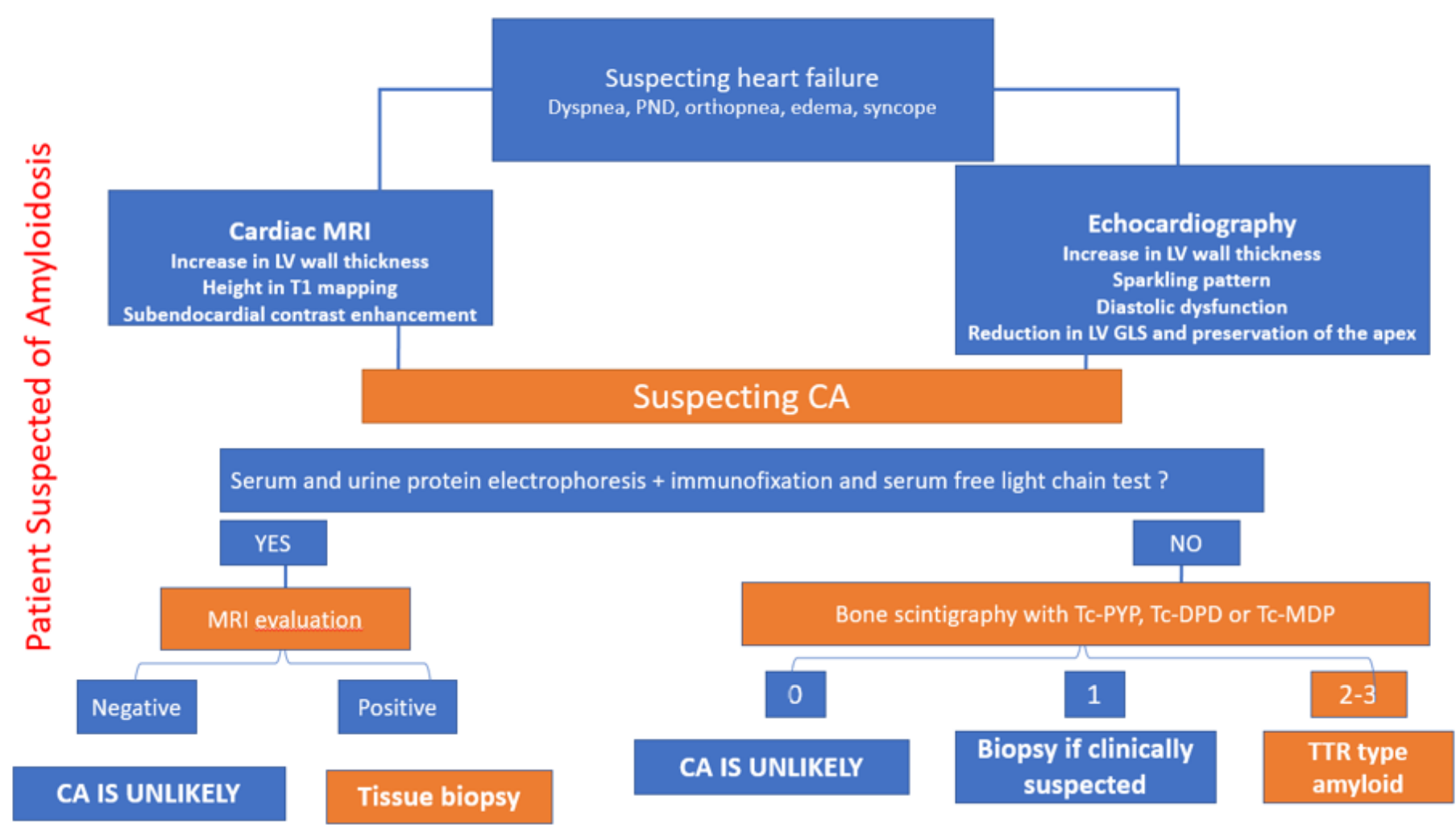

Figure 2

\section{Amyloidosis algorithm}




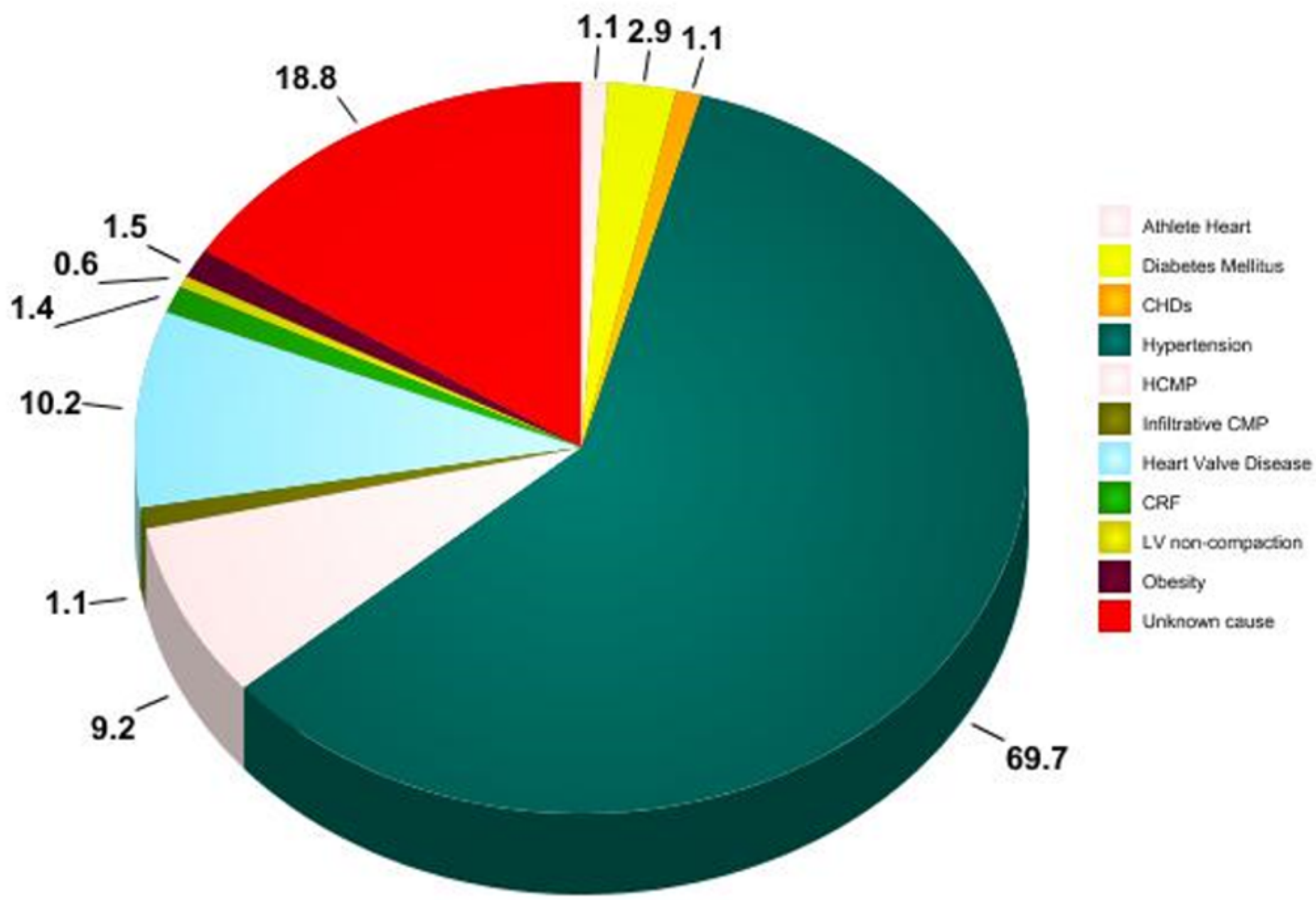

Figure 3

Etiology of LVH in Study Population 

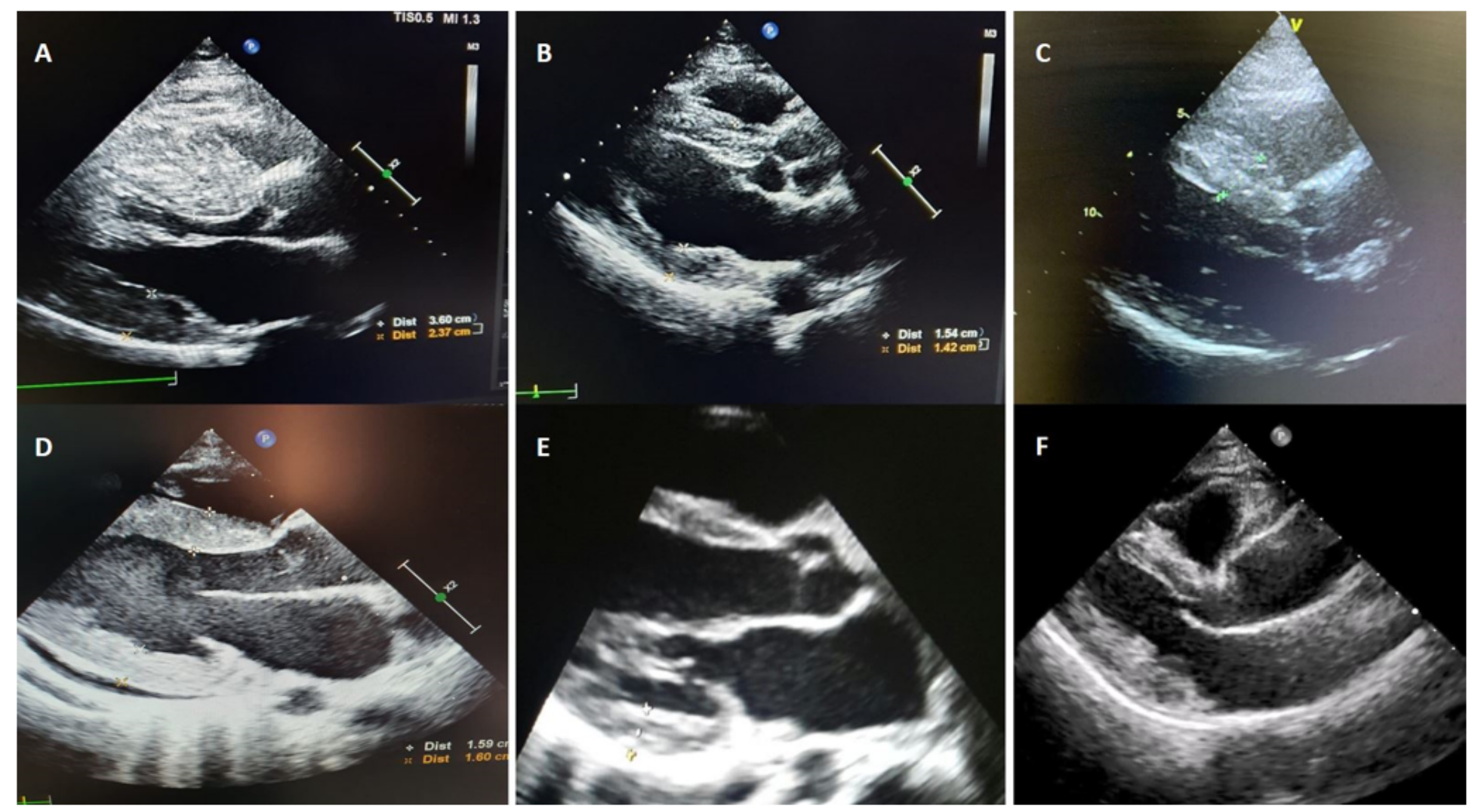

Figure 4

Echocardiographic images of different LVH etiologies. A: Fabry's disease, B: Hypertension, C: Hypertrophic cardiomyopathy, D: Chronic renal failure, E: Athlete's heart, F: Amyloidosis. 